\title{
A JUSTIÇA É TAMBÉM POLÍTICA: A PARTICIPAÇÃO DOS JUÍZES DE PERNAMBUCO NA FORMAÇÃO DO ESTADO BRASILEIRO (1835- 1871)
}

\author{
JUSTICE IS ALSO POLITICS: A PARTICIPATION OF THE JUDGES OF \\ PERNAMBUCO IN THE FORMATION OF THE BRAZILIAN STATE (1835-1871)
}

\begin{abstract}
Alexsandro Ribeiro do Nascimento ${ }^{1}$
1 Universidade Federal da Bahia, Departamento de Pós-Graduação em História, Brasil, e-mail: alexribeiro2@gmail.com
\end{abstract}

\author{
A R T I C LE IN F O \\ Article history: \\ Received 2019-06-22 \\ Accepted 2019-09-06 \\ Available online 2019-09-06
}

Palavras-chave: Política. Judiciário. Brasil. Pernambuco. Oitocentos.

Keywords: Política. Judiciário. Brasil. Pernambuco. Eight hundred.

RESUMO. Este trabalho tem o objetivo de analisar a participação de alguns juízes pernambucanos na formação do estado do Brasil desde o período regencial até a Reforma Judiciária de 1871. O debate sobre a atuação desses magistrados é importante para compreender o funcionamento das instituições políticas, uma vez que estes poderiam acumular cargos no Judiciário e nas Casas Legislativas. Uma das questões sobre a atuação destes juízes é o diálogo que eles tinham com atores de diversas instituições. Por fazerem parte de um grupo considerado privilegiado dentro da província, e também no âmbito nacional, estes magistrados estavam inseridos em redes de relações construídas e sustentadas antes mesmo da formação do Estado imperial. Afinal, não tem como pensar a Justiça e o poder sem conhecer a origem portuguesa na qual nasceram e foram desenvolvidas as normas que regeram e ainda conduziam o país por séculos. Os juízes também podem ser identificados como atores que fazem parte e alimentam a cultura política deste período. Com isso, a análise vai além da movimentação e da atuação no Judiciário. O discurso político destes personagens é fundamental para analisar o funcionamento das instituições e das relações sociais da época. Eles não serão tratados apenas como simples magistrados, mas como produtores de discursos políticos. O método do trabalho é a análise documental das instituições de Justiça no período como o Arquivo Público de Pernambuco, o Arquivo da Faculdade de Direito do Recife, e os jornais da época, bem como a análise de discurso dos magistrados.

ABSTRACT. This paper aims to analyze the participation of some judges of Pernambuco in the
formation of the state of Brazil from the regency period until the Judicial Reform of 1871 . The debate
about the performance of these magistrates is important to understand the functioning of political
institutions, since they could accumulate positions in the judiciary and the Legislative Houses. One of
the questions about the performance of these judges is their dialogue with actors from various
institutions. Being part of a group considered privileged within the province, and also at the national
level, these magistrates were inserted in networks of relationships built and sustained even before the
formation of the imperial state. After all, there is no way to think about justice and power without knowing
the Portuguese origin in which were born and developed the rules that governed and still led the country
for centuries. Judges can also be identified as actors who are part of and nurture the political culture of
this period. With this, the analysis goes beyond the movement and performance in the judiciary. The
political discourse of these characters is fundamental to analyze the functioning of the institutions and
social relations of the time. They will not only be treated as mere magistrates, but as producers of 
political speeches. The method of the work is the documentary analysis of the institutions of Justice in the period as the Public Archive of Pernambuco, the Archive of the Faculty of Law of Recife, and the newspapers of the time, as well as the discourse analysis of the magistrates.

\section{Introdução}

O Dicionário do Brasil imperial trata da importância das Academias de Direito da seguinte maneira: "Consideradas por (Joaquim) Nabuco as 'ante-salas da Câmara'; centros por excelência de formação de políticos e da administração imperial” (VAINFAS, 2002). E, de fato, as Faculdades de Direito recém-inauguradas no país, em São Paulo e Olinda, recebiam os primeiros estudantes ainda no ano de 1827 já interligados ou em busca de ascensão na vida política. Jovens que na maioria eram descendentes de proprietários de terra e da elite política e comercial da região. Esses grupos se inserem no conceito de elite instituído por Antônio Manuel Hespanha. Para o autor, todas as pessoas, de algum modo, são pertencentes à elite porque 'todos temos algum grupo que nos reconhece, para o bem ou para o mal, como detentores de uma legitimidade para dirigir em alguns dos planos da inter-acção social" (HESPANHA, 2005). Já para Flávio Heinz as perspectivas sobre os estudos das elites são suficientemente abertas para serem utilizadas em diversos tipos de investigações. Esse tipo de análise ajuda em um tratamento sociológico das elites. É um estudo que não se afasta da perspectiva histórica (HEINZ, 2006).

Estes magistrados recém-formados contribuíram para a manutenção das instituições e da ordem vigente do império. Isto é, ao chegarem nos postos administrativos e políticos da burocracia estatal os bacharéis auxiliaram no fortalecimento do governo ${ }^{1}$. Por estarem sempre em contato com as elites locais e também inseridos neste grupo, os profissionais da lei eram uma das principais pontes de diálogo entre grupos regionais e a corte. Estes operadores do Direito através do treinamento e socialização auxiliaram na centralização governamental. 0 sistema burocrático do período era dividido por funções, verticalmente, e pela estratificação salarial hierárquica, de maneira horizontal (CARVALHO, 1980).

É importante afirmar que os interesses particulares não eram de todo ignorados. Estes atores jurídicos por vezes questionavam as decisões vindas da corte. Este tipo de atitude evidenciava rixas políticas principalmente entre grupos conservadores e liberais o que culminou, por exemplo, na Insurreição Praieira em Pernambuco.

Alguns juízes tiveram relações com fatos que antecederam o episódio praieiro. Diante de documentações da época, constatamos que esses magistrados estavam inteirados das

\footnotetext{
${ }^{1}$ Em meados do século XIX, o termo bacharel, junto com o magistrado, podia ser utilizado por pessoas que já haviam exercido em algum momento de sua vida a função de profissional da lei. A nossa preocupação é distinguir esse cargo e focar somente nos formados em Direito. Ver conceito de bacharel em CARVALHO, José Murilo de. A construção da ordem: a elite política imperial. Rio de Janeiro: Campos. 1980, p. 217.
} 
movimentações no interior e na capital da província. Em alguns casos, foram protagonistas e utilizaram armas a favor ou contra os rebeldes. Além disso, participaram de diversos julgamentos depois da insurreição (NASCIMENTO, 2014).

Com isso, as movimentações destes profissionais da lei, que estiveram presentes nos mais significativos eventos políticos e sociais da província, como a questão dos processos judiciais de africanos e a própria Insurreição Praieira são imprescindíveis para analisar o funcionamento das instituições de Justiça em Pernambuco².

Uma das questões sobre a atuação destes operadores do Direito é o diálogo que essas figuras mantinham com outros atores de diversas instituições. Por fazerem parte de um grupo considerado privilegiado dentro da província pernambucana, e também no âmbito nacional, esses juízes estavam inseridos em redes de relações construídas e sustentadas antes mesmo da formação do Estado Imperial. Afinal, não tem como pensar a Justiça e o poder sem conhecer a origem portuguesa na qual nasceram e foram desenvolvidas as normas que regeram e de certa forma ainda conduziram o país por séculos ${ }^{3}$.

Diante disso, é possível diagnosticar que a proximidade de diversos personagens da área do Direito com outras figuras públicas colocava-os como sujeitos propensos a julgar, analisar e apreciar as leis ao seu modo. $\mathrm{E}$ ainda: os próprios bacharéis e outros personagens da burocracia imperial poderiam ser confundidos. Pela acumulação de cargos os magistrados eram responsáveis pela elaboração, aplicação e punição através das leis (cf. COLEÇÃO DE LEIS DO IMPÉRIO DO BRASIL DE 1831).

Para explicar esse funcionamento da justiça e o discurso político dos juízes primeiro iremos realizar uma análise conceitual dos termos sobre a cultura política e cultura jurídica e depois será exemplificado a atuação, o discurso e o comportamento político destes profissionais da lei em Pernambuco.

\section{Cultura política $X$ cultura jurídica brasileira}

Antes de adentramos na discussão principal do presente capítulo é necessário distinguir as concepções de Direito e Justiça tratados na pesquisa: o primeiro é abordado aqui

\footnotetext{
${ }^{2}$ Com o decreto de novembro de 1835, o serviço dos africanos deveria ser realizado perante o juiz de órfãos e não mais em praça pública. Seus serviços deveriam ser prestados nos municípios de cada província. Cada pessoa poderia adquirir no máximo oito africanos. De acordo com a Lei de 7 de novembro de 1831, o tráfico de escravos era proibido e os africanos que desembarcassem no Brasil eram considerados livres a partir de então. No entanto, estes teriam que servir no prazo de 14 anos na condição de "criados" - como se fosse um aprendizado - para depois conseguirem sua liberdade. Ver em Coleção das Leis Império do Brasil 1835. Parte Segunda. Rio de Janeiro. Tipografia Nacional. 1864; Coleção de Leis do Império do Brasil de 1831. Rio de Janeiro: Tipografia Nacional, 1878

${ }^{3}$ De acordo com Jonas Moreira Vargas, as redes devem ser empregadas como vínculos de duração limitada. Para ele, o historiador precisa identificar as redes enquanto elas estiveram funcionando, pois do mesmo jeito que elas são construídas, elas podem ser rompidas após "cumprirem" seus resultados pessoais e coletivos. É no conceito de rede do autor que desenvolveremos o nosso trabalho. VER em VARGAS, Jonas Moreira. Entre a paróquia e a Corte: a elite política do Rio Grande do Sul (1850-1869), Santa Maria: UFSM. 2007.
} 
dentro das compreensões mais gerais do Estado. Ele é uma espécie de regulação; já o segundo termo é uma qualidade que pode ser exteriorizada por meio da ação de um indivíduo. A justiça vai além das regras do Direito, dos atos administrativos, ela pode agir em múltiplas ações onde pode atribuir a cada qual aquilo que lhe é devido (ANTUNES, 2013).

Por conseguinte, como a Justiça e política caminharam juntos na formação do Estado brasileiro é compreensível a confusão dos termos da cultura política e jurídica no período. Considerados figuras notáveis, os juízes participavam ativamente das discussões sobre a melhoria da província pernambucana.

A cultura política é definida por Jean-François Sirinelli como uma espécie de código e de um conjunto de referentes formalizados no seio de um partido ou difundidos na família e até pelas tradições políticas (RIOX; SIRINELLI, 1998). Já para Serge Berstein a cultura política é plural, com valores partilhados, e em alguns momentos da história pode existir uma cultura política determinante em uma região. Para ele, a cultura política "é um corpo vivo que continua a evoluir, que se alimenta e se enriquece com múltiplas contribuições de outras culturas políticas". E ainda o termo pode ser entendido como uma união coerente em que todos os elementos estão em estreita relação uns com os outros, permitindo assim definir a forma do indivíduo que dela se reclama (BERSTEIN, 1998).

Vale lembrar ainda que, segundo Berstein, em vários momentos da história a cultura política não tem a mesma audiência, ou seja, muitas vezes interessa a apenas grupos minoritários. Segundo o autor, também há culturas políticas dominantes que atendem a interesses majoritários da sociedade na qual "parecem traduzir os anseios da maioria e porque elas oferecem respostas aparentemente pertinentes para os problemas do momento" (BERSTEIN, 2009).

O estabelecimento das culturas políticas ocorre de maneira lenta e se torna operacional quando grupos importantes de uma determinada região as aderem. Os discursos vão se habituando entre atores estratégicos e acabam se interiorizando. Através desses procedimentos a sociedade cria seu comportamento político (BERSTEIN, 2009).

O substrato filosófico, que também move uma cultura política, é um elemento que pode tornar a sociedade simpática a uma determinada corrente política e/ou econômica. Nas sociedades antigas e medievais a religiosidade era responsável pelo comportamento dos indivíduos. Já correntes como o iluminismo e, consequentemente, o liberalismo eram as doutrinas mais admiradas e seguidas por diversas figuras públicas do final do século XVIII e no decorrer do XIX. Estas últimas eram o motor das opiniões críticas e do funcionamento das instituições brasileiras na qual os juízes tinham papel considerável.

Já a cultura jurídica brasileira deve ser compreendida, em princípio, por aderir os ensinamentos da Universidade de Coimbra. As primeiras turmas das Faculdades de Direito 
do Brasil bebiam do conhecimento português uma vez que vários professores dos novos espaços de ensino tinham se formado na antiga metrópole. Além disto, a estrutura curricular dos novos órgãos era bastante parecida com a de Coimbra. No entanto, a principal função dessas instituições era fazer o país ganhar autonomia as práticas de estudo de Portugal.

No primeiro ano estudava-se as disciplinas de Direito Natural, público, análise da constituição do Império, Direito das gentes e diplomacia. No segundo ano o Direito Público e Privado, além da continuação das disciplinas do ano anterior. O terceiro ano tinha a disciplina de Direito pátrio civil e Direito pátrio criminal com a teoria do processo criminal. Já no quarto ano as disciplinas eram Direito mercantil e marítimo e a continuação do Direito Pátrio Civil. Por último, no quinto ano, estudava-se Economia Política e Teoria e prática do processo adotado pelas leis do Império (cf. LEI DE AGOSTO DE 1827).

Vale lembrar que os novos rumos acadêmicos e consequentemente políticos não sairiam somente de Coimbra, Paris, Inglaterra, Alemanha e outros países europeus. Eles passaram também a existir e ser debatidos nas ladeiras do centro histórico de Olinda. Tanto em terras pernambucanas como nas paulistas, os aspirantes a magistrados ampliaram o quadro intelectual e político do Brasil. Alguns desses acabaram tornando-se estadistas e ajudaram na manutenção da unidade nacional. Os estudantes vindos de Portugal não estavam sós nesse desafio. Eles contavam com um reforço à altura para a estabilização do Império. Contudo, mesmo com a instalação das faculdades, os bacharéis formados em Coimbra, em sua maioria, predominaram na consolidação da política imperial.

A vigência das Ordenações Filipinas e da legislação portuguesa colonial ainda pairavam nos ensinamentos das instituições de ensino. No entanto, existiram aspirações por um conjunto de ideias novas brasileiras inspiradas nas revoluções liberais que estavam presentes nas discussões e movimentações dos intelectuais do país. O próprio Código Criminal de 1830 é o maior exemplo disto. Esse conjunto de leis era próximo das ideias liberais da época e teve uma considerável repercussão internacional, sendo elogiado por vários magistrados de diferentes países, era chamado de um modelo clássico que deveria ser desenvolvido pelas nações "civilizadas" (LOPES, 2009).

A cultura jurídica brasileira, como também em boa parte do mundo ocidental, se espelhava no Liberalismo. Porém no país existiam suas peculiaridades. O Estado era autoritário, oligárquico e se sustentava pela mão-de-obra escrava. Para Vanessa Spinosa, a cultura política dirigente do império trazia:

"contradições, avanços e retrocessos, na empreitada de tentar harmonizar constitucionalismo, monarquia, escravidão, liberalismo e patrimonialismo. E a cultura jurídica dialogou diretamente com estes percursos, submetendo-se a lógica conservadora, mesclada em um liberalismo autoritário que projetava 'um direito nacional' limitador de um projeto de modernização para a doutrina jurídica (SPINOSA, 2013). 
Por conseguinte, o Direito aqui instalado foi readaptado e seguido pela maioria do corpo jurídico formado nas Faculdades de São Paulo e Olinda: "a cultura jurídica brasileira, assim, será produto desta tensão que só pode ser percebida nesse palco histórico" (FONSECA, 2005).

Por conta dessa lentidão, a modernização, segundo Mozart Linhares, foi moderada, amenizada, e deixada de lado em muitas regiões (SILVA, 2004). Uma das razões disso foi a política de restrição das elites locais que continuou vigorando por bastante tempo. Era a coação do interesse familiar. Esses grupos não queriam perder os privilégios que tinham nas instituições e, com isso, a organização política-administrativa do Império manteve-se excludente. Dimas José Batista chega a dizer que o Estado brasileiro todo-poderoso era uma "ficção" (BATISTA, 2006).

Com isso fica claro que o exercício do Direito não pode ser visto como repressivo e de técnicas vazias. A prática jurídica é movida por valores essenciais da sociedade. Na teoria, ela deve ser exercida em prol dos "injustiçados", por mais que na prática, evidenciado no século XIX, ela seja regida por poucos e de interesses a algumas cúpulas locais. De acordo com Mozart Linhares, existia no código penal uma concepção dualista, que compreendia a sociedade como duas metades, a "civilizada"/ livre e a escrava/corruptora. Era uma norma ambígua que acabava mantendo o aparelho social vigente. As pessoas do "alto escalão" da sociedade sofriam punições brandas em relação aos escravos ou vadios (SILVA, 2003).

Os percalços da prática liberal jurídica esbarravam já na Faculdade. Disciplinas como Direito Eclesiástico e o tom conservador dado a cadeira de Direito Natural mostravam que as raízes e práticas do antigo regime ainda iriam perdurar por um bom tempo na sociedade oitocentista. Para Ricardo Fonseca, esses exemplos mostram a dificuldade da construção de uma cultura jurídica brasileira. Esta, segundo ele, "ainda não tinha condições de sair de sua situação de um casulo" (FONSECA, 2005).

A mudança e o crescimento de uma autonomia jurídica brasileira ocorreram na segunda metade do século XIX sobretudo com o fim do tráfico negreiro pela lei de 4 de setembro de 1850. O afastamento da matriz portuguesa, com a inserção da disciplina de Direito Romano nas Faculdades, além do prestígio que alguns bacharéis brasileiros conseguiram obter logo depois da formação das primeiras turmas, auxiliaram no fortalecimento da "modernidade brasileira".

No geral, a cultura jurídica brasileira foi formada pela tensão entre os anseios liberais e a característica oligárquica do Estado. Os conteúdos ensinados nas faculdades e outras questões externas, como o próprio engajamento político de vários de seus estudantes, fizeram parte também da formação desta cultura jurídica. 
Por conseguinte, a cultura política e a cultura jurídica brasileira no século XIX foram se moldando até meados do oitocentos. Neste percurso os discursos políticos e a prática jurídica começaram a se dissociar, principalmente no distanciamento com o a antiga metrópole. Com isso, os atores das instituições de justiça e do governo foram ocupando espaços separados, mesmo que na prática eles ainda estavam próximos e com uma sintonia significativa. E ainda:

\begin{abstract}
"'A cultura jurídica brasileira' aqui não pode ser aferida consoante critérios de "melhor" ou "pior", de "mais" ou "menos" refinamento intelectual, mas sim como o conjunto de padrões e significados que circulavam e prevaleciam nas instituições brasileiras do Império (faculdades, institutos profissionais de advogados e magistrados, o foro e, em alguns casos, no parlamento), e que atribuíam uma tipicidade ao direito brasileiro" (FONSECA, 2005).
\end{abstract}

A proximidade da Justiça e política brasileira era tão notória nos cursos de Direito recém-inaugurados que até o projeto para a regulamentação das Faculdades, elaborado pelo decreto de 9 de janeiro de 1825, organizado pelo Conselheiro do Estado Visconde de Cachoeira, citava a pretensão das novas instituições de ensino em formar figuras públicas que ajudassem na administração do governo:

"(...)se formarem homem hábeis para serem um dia sábios Magistrados, e peritos Advogados, de que tanto se carece; e outros que possam vir a ser dignos Deputados, e Senadores, e aptos para ocuparem os lugares diplomático, e mais emprego do Estado, por se deverem compreender nos estudos do referido Curso Jurídicos os princípios elementares de direito natural, público, das gentes, comercial, político e diplomático, é de forçosa, e evidente necessidade, e utilidade formar o plano dos mencionados estudos (...)" (LEI DE AGOSTO DE 1827).

Os alunos deveriam ser, antes de tudo, grandes humanistas, com sede do saber e pela vivência do mundo. A preocupação com esse tipo de ensinamento ficou evidente no discurso realizado no dia da inauguração da Faculdade de Olinda, pelo diretor interino Doutor Lourenço José Ribeiro: “(...) estão abertas nessa província os tesouros da sabedoria. Os jovens e caros concidadãos devem procurar as fontes das luzes”. (VEIGA, 1980).

\title{
3. Discurso político e atuação jurídica em Pernambuco do oitocentos
}

Diante das explanações sobre a cultura política e jurídica brasileira podemos analisar o discurso e o comportamento político dos juízes pernambucanos formados nas primeiras turmas da Faculdade de Direito de Olinda. Iremos utilizar o conceito de discurso político de Pocock que atrela o termo a uma série de "linguagens" e modos de argumentação vindos de várias origens (POCOCK, 2003). No nosso estudo de caso, iremos restringir os discursos políticos as manifestações dos Operadores do Direito ligadas a instituições, administrações e demais membros da sociedade que estavam inseridos aos assuntos públicos e de interesses do governo do Brasil no século XIX. 
Como a atuação dos magistrados caminhava junto as figuras com bastante representatividade local, praticamente toda movimentação que envolvia os bacharéis era ligada as discussões políticas. Qualquer discurso na Assembleia Provincial ou Geral, quando exerciam a função de deputados; no debate com chefes locais em várias regiões de Pernambuco; e até artigos escritos nos jornais da época. Nenhum episódio pode ser colocado a margem da análise do comportamento político.

A primeira turma da Faculdade de Direito em Olinda se formou em 1832 e os bacharéis estavam inseridos no contexto do período regencial, época de crise de representatividade do governo brasileiro e, particularmente, em Pernambuco as movimentações políticas eram intensas diante de um cenário posterior a Revolução Pernambucana de 1817 e a Confederação do Equador, além de anteceder a Insurreição Praieira.

Como nossa análise vai até a Reforma Judiciária de 1871, vários bacharéis se formaram neste período. Levando em conta que em média concluíam aproximadamente 50 alunos desde 1832, mais de dois mil alunos estavam aptos a Operadores do Direito. A pesquisa ficou restrita por dois motivos principais: o primeiro era o número de pernambucanos que estavam ingressos na Faculdade de Direito de Olinda. Para se ter uma ideia até 1860, dos 1448 alunos formados, 479 eram nascidos na província, representando um terço dos discente. Nesse período entre 1835 e 1860, 374 formados eram da Bahia, 102 da Paraíba, 95 do Ceará, 95 do Maranhão, 80 do Rio de Janeiro, 48 de Alagoas, 34 do Pará, 31 do Sergipe, 31 do Piauí, 22 do Rio Grande do Norte e outros 22 do resto do Brasil e também do exterior. Isso comprova a importância dos ensinamentos do espaço acadêmico local que se perpetuou por boa parte do país ${ }^{4}$.

O segundo é a quantidade de pessoas que exerceram os cargos de juízes. Por conta da diversidade e do caráter provisório de algumas funções da magistratura é praticamente impossível chegarmos a um número exato 5 . Além disso, vários desses personagens seguiram somente a carreira advocatícia, principalmente com a instalação do Instituto dos Advogados

\footnotetext{
${ }^{4}$ VER em Arquivo da Faculdade de Direito do Recife: Lista geral dos bacharéis e doutores (1828 - 1931).

${ }^{5}$ Dentro do período proposto do trabalho ocorreram duas mudanças significativas dentro do Código do Processo Criminal de 1830 e que contribuiu para novas funções ao Poder Judiciário: A promulgação do Código em 1832 e sua reformulação em 1841. Com a Reformulação do Código de Processo Criminal em 1841, na qual a proposta de centralização seguia ainda mais forte, os juízes municipais tinham as funções de: conceder fiança aos réus que pronunciassem ou prendessem; acumular atribuições criminais e policiais que eram competentes aos juízes da paz; sustentar ou revogar as pronúncias feitas pelos delegados e subdelegados; julgar suspeições aos delegados; além de substituir na comarca o juiz de direito na sua falta ou impedimento. Eles passaram a ser nomeados pelo Imperador entre os bacharéis formados em Direito, com no mínimo um ano de experiência na área. O cargo era ocupado por no máximo quatro anos e o salário podia chegar até quatrocentos mil réis. Já os juízes de direito eram recrutados dentre bacharéis formados que tivessem servido com distinção nos cargos de juízes municipais, de órfãos ou de promotores públicos por, no mínimo, quatro anos. Entre suas funções estavam: a análise dos processos crimes sentenciados pelos juízes municipais, delegados e subdelegados, no qual poderiam condenar ou absolver réus por prevaricação, corrupção ou suborno. Eles também estavam à frente de Tribunais de Júri e podiam aplicar o Habeas Corpus, novidade na época. Ver Lei № 261, de 3 de dezembro de 1841. Reforma do Código do Processo Criminal. Disponível em http://www.planalto.gov.br/ccivil 03/Leis/LIM/LIM261.htm. Acessado em 25 de junho de 2019.
} 
Brasileiros em 1843. Já outros podiam ficar restritos a carreira política e até em negócios da família. Por exemplo, Gervásio Gonçalves da Silva, que preferiu se ocupar com questões familiares e cuidar de seus patrimônios como proprietário de terra por um tempo- prática comum entre clãs que compartilhavam atividades econômicas com os entes. Mesmo assim, por ser neto e apadrinhado de um ex-presidente da província, Gervásio Pires Ferreira, ele foi um dos responsáveis por conduzir o processo o julgamento de um dos líderes da Insurreição Praieira, o general Ignácio Abreu e Lima. No entanto, não quer dizer que vários outros bacharéis, principalmente os que não tinham parentesco político, deixaram a carreira de lado (NASCIMENTO, 2014).

Através da análise documental percebemos que os juízes do período chegavam a atuar em conjunto. A formação na mesma Faculdade de Direito e a proximidade de famílias mostra que existia uma teia de relacionamento entre esses magistrados. Com isso, alguns dos profissionais da lei se "destacavam" nos ofícios enviados ao presidente da província e nos discursos e artigos retratados nos jornais da época. Nessa documentação podemos compreender a movimentação de importantes atores sociais e instituições que moviam a sociedade, como também de legitimar o poder do Estado recém-criado.

Entre eles podemos destacar a atuação de Francisco Rodrigues Sette. Natural de Pernambuco e filho de Francisco Feliciano Rodrigues Sete ele concluiu o curso de Ciências Jurídicas e Sociais no ano de 1839 e tornou-se promotor público na vila de Limoeiro em 16 de fevereiro de 1841, porém, assumiu outros cargos, como o de juiz de direito e juiz municipal em Olinda e Recife. Além do cargo de promotor público de Limoeiro, ele foi juiz de direito interino da $3^{\underline{a}}$ vara do Cível do Recife em 28 de fevereiro de 1842, juiz municipal de Olinda em 30 de março de 1842, juiz municipal da $1^{\text {a }}$ vara do Recife em 30 de agosto de 1842, juiz Municipal e dos órfãos do termo de Rio Formoso em 13 de junho de 1849, 6o suplente de juiz municipal da $2^{\underline{a}}$ vara do termo do Recife em 22 de fevereiro de 1849, juiz Municipal da $2^{\underline{a}}$ vara do Recife em 19 de novembro de 1849 e juiz municipal da $2^{a}$ vara do Recife em 1 de abril de 1852 (NASCIMENTO, 2014).

Por estar imerso no período entre a Insurreição Praieira e o período de Conciliação de Pernambuco, Sette não conseguiu fugir dos ataques dos liberais. Antes mesmo dos acontecimentos entre os anos de 1848 e 1849, o magistrado mostrava estar ao lado dos conservadores. Chegou a ser repudiado pelo julgamento do editor do Diário Novo, Basilio Alvares de Miranda Varejão, quando ocupava o cargo de juiz do direito interino do Recife $O$ periódico era ligado aos praieiros. Anos depois disse não garantir "segurança necessária" para a reunião da Sociedade Liberal, grupo composto por ex-militantes do partido praieiro. Segundo ele, esta associação, queria "destruir a constituição do império" (cf. Diário de Pernambuco, 1852). 
Aliás, o pronunciamento em prol do governo e da manutenção da ordem era uma das características principais do discurso dos juízes. A maioria estava ao lado, obedecia aos pedidos da corte e repudiavam qualquer tipo de atitude que fosse de encontro as leis estabelecidas. Como deputado geral e também membro da magistratura pernambucana, Joaquim Vilella de Castro Tavares repelia os atos das pessoas que contestavam a autonomia do Estado imperial. Ele critica a atuação do jornalista Borges da Fonseca, que se tornou um dos principais líderes da Insurreição Praieira. Tavares era irmão de Jerônimo Villela Tavares, estava ao lado dos rebeldes, e ficou conhecido pela famosa quadra: "Quem viver em Pernambuco/Deve ser desenganado/ Que ou há de ser Cavalcanti/ Ou há de ser cavalgado". Nesse caso a fidelidade com o governo (ou interesse pessoal) se sobressaía as relações familiares, pelo menos na teoria. (MARSON, 1980).

Os juízes eram personagens ativos no meio político nesse período e se defendiam e contra-atacavam acusações que recebiam. Como no caso do juiz municipal da comarca de Limoeiro, José Francisco da Costa Gomes, que se defendeu das acusações de liberais por conceder vários habeas corpus. Seus opositores diziam que as decisões eram movidas por "paixões políticas". Já o magistrado se acobertava através da lei que era "justa as pessoas de bem" (cf. DIÁRIO NOVO, 1846).

Nos diversos casos que podem ser analisados no período logo após a criação do Código Criminal, ainda no período Regencial, é possível que esses juízes não levassem à risca as novas leis. Contudo, isso não era empecilho para o funcionamento das instituições e da manutenção da normalidade das regiões que atuavam. O magistrado funcionava também como mediador de conflitos e tentava manter a ordem sem prejudicar qualquer membro da elite local, mesmo que fosse flexível com as recentes normas aplicadas em espaços que já possuíam seus próprios costumes. Quem iria de encontro aos interesses dos grupos locais poderia sofrer perseguições, como no caso do juiz municipal de Igarassu, Luiz Duarte Pereira, que se envolveu em algumas confusões com delegados e subdelegados da região. Por conta disso, o magistrado acabou sendo transferido para outra localidade (NASCIMENTO, 2014).

Já outros magistrados se destacaram na produção intelectual do período. Entre eles podemos citar Vicente Ferreira Gomes responsável pela elaboração da obra Guia do Processo Criminal. O trabalho, sobre atribuições policiais e criminais, serve como orientação para facilitar aos que não são especialistas no estudo do direito como os delegados, subdelegados, juízes municipais e seus suplentes.

Outro que ganhou destaque no campo intelectual foi Vicente Pereira do Rego. Ele publicou, em 1857, os "Elementos de Direito Administrativo Brasileiro", comparado com o Direito Administrativo Francês. Consagrado especialmente à sua finalidade didática, 0 trabalho do bacharel, que também chegou a exercer o cargo de professor na Faculdade de 
Direito, explana uma visão geral do direito brasileiro nos meados do século XIX. Com a sua produção acadêmica ele foi o pioneiro da América Latina sobre os estudos do Direito Administrativo.

\section{Considerações finais}

São nesses casos que os juízes podem ser identificados como personagens da cultura política desse período da história do Brasil. No qual os sujeitos se entrelaçavam amistosamente ou por rixas dentre diversos motivos desde a discussão pela arrematação de africanos livres até conflitos por terras ou motins contra o governo.

Por conseguinte, a análise no presente trabalho do Judiciário em Pernambuco vai além da movimentação e da atuação no campo jurídico e revela as especificidades desta atuação em outras partes do país. O discurso político destes personagens é fundamental para compreender o funcionamento das instituições e das relações sociais. Estes atores não serão tratados apenas como simples magistrados, mas, sobretudo, como produtores de discursos políticos.

Além dos juízes citados, vários outros magistrados podem contribuir para uma análise da atuação jurídica de Pernambuco. Fizemos levantamento de outros personagens que obtém características semelhantes como a descendência política e a posse de engenhos. Esses demais profissionais da lei serão explanados em trabalhos posteriores

Com as questões e hipóteses levantadas sobre a análise histórica a serem feitas pelos juízes no século XIX fica evidente que independente de tratar sobre a cultura política destes personagens e de sua atuação no Judiciário, o desafio é investigar os rastros e vestígios deixados em seus discursos nas diversas fontes do período. É tentar preencher as lacunas com os sinais que podem ser identificados nas documentações e levantar indagações sempre que possíveis das relações sociais que permearam na província pernambucana.

A análise das relações jurídicas e também políticas entre esses diversos atores mostra a proximidade que a elite tinha no período e acabava formando um perfil de atuação. Estas características não estão retidas somente ao período imperial brasileiro. A peculiaridade das movimentações jurídicas são atributos em vários períodos da história do Brasil, como, por exemplo, na aplicabilidade da lei feita por membros da Lava Jato. Os magistrados à frente da operação iniciada em 2014, que mudaram a realidade política do país com investigações de lavagem de dinheiro que movimentou bilhões de reais em propina, estão interligados através de uma teia oligárquica. $A$ identificação foi elaborada através do método prosopográfico pelo professor de Sociologia da Universidade Federal do Paraná, Ricardo Costa de Oliveira. É por este procedimento que é possível criar uma biografia coletiva e definir o perfil de determinados grupos. O objetivo é entender se existe uma espécie de "padrão" de características entre 
esses atores, o que pode ter feito esse grupo agir de acordo com seus próprios interesses (HEINZ, 2006). Isso prova que a arte de enxergar o passado através do presente é primordial no fazer histórico ${ }^{6}$.

\section{REFERÊNCIAS}

BERSTEIN, Serge. Culturas políticas e historiografia. In. Cultura política, memória e historiografia / Orgs. Cecília Azevedo... [et al.]. Rio de Janeiro: Editora FGV, 2009 p. 37. ANTUNES, Álvaro Araújo. As paralelas e o infinito: uma sondagem historiográfica acerca da História da Justiça na América Portuguesa. Revista de História São Paulo, № 169, p. 21-52, julho / dezembro 2013.

APEJE- Arquivo Público Estadual Jordão Emerenciano: Coleção Juízes Municipais (JM1835 - 1871); Coleção Juízes de Direito (JD - 1835 - 1871).

Arquivo da Assembleia Legislativa de Pernambuco: Anais (1835-1871); Atas das Sessões Legislativas de Pernambuco (1849-1871); Leis do Estado de Pernambuco (1850-1871). ARQUIVO DA FACULDADE DE DIREITO DO RECIFE: Lista geral dos bacharéis e doutores (1828 -1931); Livro de certidões de idade (1829 - 1831); Livro de certidões de idade (1832 - 1835); Livro de certidões de idade (1836 - 1839); Livro de registro de diplomas de bacharéis e doutores (1833 - 1925); Livro de registro de matrículas do 3 ㅇ ano (1830 - 1868); Livro de registro de diplomas de bacharéis expedidos pela Academia Jurídica de Olinda (1832 - 1848).

BATISTA, Dimas José. A administração da justiça e o controle da criminalidade no Médio Sertão do São Francisco, 1830-1880. Tese (doutorado). São Paulo: Universidade de São Paulo, Programa de pós-graduação em História, 2006.

BERSTEIN, Serge. "A cultura política". In RIOUX SIRINELLI (Org.) Para uma História Cultural. Lisboa: Editora Estampa, 1998.

CARVALHO, José Murilo de. A construção da ordem: a elite política imperial. Rio de Janeiro: Campos. 1980.

COLEÇÃO DAS LEIS IMPÉRIO DO BRASIL 1835. Parte Segunda. Rio de Janeiro. Tipografia Nacional. 1864; Coleção de Leis do Império do Brasil de 1831. Rio de Janeiro: Tipografia Nacional, 1878.

COLEÇÃO DE LEIS DO IMPÉRIO DO BRASIL 1841 E 1871. Disponível em http://bd.camara.gov.br/bd/handle/bdcamara/18299/browse?type=title.

COLEÇÃO DE LEIS DO IMPÉRIO DO BRASIL DE 1831. Rio de Janeiro: Tipografia Nacional, 1878.

Coleção de periódicos e jornais da Biblioteca Nacional - Disponível em: http://memoria.bn.br/hdb/uf.aspx.

FONSECA, Ricardo. A Formação da Cultura Jurídica Nacional e os Cursos Jurídicos no Brasil: Uma análise preliminar (1854-1879). Cuardenos del Instituto Antonio de Nebrija, 8, 2005 HEINZ Flávio M. (org). Por outra história das elites. FVG editora. Rio de Janeiro. 2006. HESPANHA, Antônio Manuel. Governo, elites e competência social: sugestões para um entendimento renovado da história das elites. In: BICALHO, Maria Fernanda. FERLINI, Vera Lúcia Amaral (orgs.) Modos de Governar. Ideias e Práticas Políticas no Império Português - séculos XVI a XIX. São Paulo. Almeida, 2005.

INSTITUTO ARQUEOLÓGICO, HISTÓRICO E GEOGRÁFICO PERNAMBUCANO (IAHGP): Coleção inventários e testamentos (1865-1878).

\footnotetext{
${ }^{6}$ A divulgação da pesquisa de Oliveira foi feita no site da Unisinos, mas o trabalho ainda será apresentado no ano
} de 2019 (cf. UNISINOS, 2019). 
LEI DE AGOSTO DE 1827. Disponível em https://www2.camara.leg.br/legin/fed/lei sn/18241899/lei-38401-11-agosto-1827-566698-publicacaooriginal-90225-pl.html. Acesso em 25 de junho de 2019.

LOPES, José Reinaldo de Lima. O Direito na História: Lições Introdutórias. São Paulo: Max Limonad, 2009

MARSON, Izabel Andrade. O império do progresso: A revolução praieira. São Paulo: Brasiliense, 1987.

MEMORIAL DE JUSTIÇA DE PERNAMBUCO: Processos Judiciais (1849-1880).

NASCIMENTO, Alexsandro Ribeiro de. "Sob o Império da Lei: a atuação dos juízes municipais na comarca do Recife (1841-1850)". Dissertação (Mestrado em História) Universidade Federal Rural de Pernambuco, Recife. 2014.

OLIVEIRA, Paulo Salles de. Caminhos de construção da pesquisa em ciências humanas. In: (Org.). Metodologia das Ciências Humanas. São Paulo. Hucitec/UNESP, 1998.

POCOCK, J.G.A. Linguagem do Ideário Político. Sergio Miceli (org.); tradução Fábio Fernandez. - São Paulo: Editora da Universidade de São Paulo, 2003.

RIOX, Jean-Pierra. SIRINELLI, Jean -François. Para uma História Cultural. Lisboa: Editora Estampa, 1998.

ROSANVALLON, Pierre. Por uma história conceitual do político. Revista Brasileira de História, São Paulo, v. 15, n.30, 1995.

SILVA, Mozart Linhares da. O império dos bacharéis: o pensamento jurídico e a organização do Estado-Nação no Brasil. Curitiba: Juruá, 2004.

INSTITUTO HUMANISTAS UNISINOS. Surge a teia oligárquica da operação. Porto Alegre, 15 de março. Disponível em http://www.ihu.unisinos.br/78-noticias/587451-surge-a-teiaoligarquica-da-operacao. Acesso em 07 de julho de 2019.

SPINOSA, Vanessa. Cultura jurídica e cultura política nos trópicos: um estudo sobre o caso brasileiro no contexto da independência. Mneme - Revista de Humanidades. Caicó, v. 14, n. 32, p. 1-21, jan./jul. 2013.

VAINFAS. Ronaldo (org). Dicionário do Brasil Imperial. Rio de Janeiro: Objetiva, 2002.

VARGAS, Jonas Moreira. Entre a paróquia e a Corte: a elite política do Rio Grande do Sul (1850-1869), Santa Maria: UFSM, 2007.

VEIGA, Gláucio. História das ideias da Faculdade de Direito do Recife. Recife: Ed. Universitária, 1980. 